\title{
ON NUMERICAL METHODS FOR ONE PROBLEM OF MIXED TYPE
}

\section{S. SYTOVA}

Institute for Nuclear Problems, Belarussian State University

Bobruiskaya 11, 220050 Minsk, Belarus

E-mail: sytova@inp.minsk.by

Received October 1, 2001

\begin{abstract}
This article is devoted to further investigation of numerical methods for one differential problem of mixed type. We consider a two-dimensional first-order differential equation with one complex-valued and one real constant coefficients. So, we have an elliptic problem with respect to the first argument and a hyperbolic problem with respect to the second one. The equations of such type are generalized transfer equations. Firstly, the correctness of the problem stated is discussed. Secondly, possible difference scheme of the multicomponent modification of the alternating direction method is proposed. Its stability and convergence is investigated. Results of numerical experiments on modelling of nonlinear regime of surface volume free electron laser are analyzed.
\end{abstract}

\section{INTRODUCTION}

The problem considered here arose in modelling of surface scheme of volume free electron laser (VFEL). Surface scheme can be realized for visible range of wavelength [2] and millimeter and sub-millimeter range [3]. In such a scheme a relativistic electron beam passes close to the surface of a target and the Cherenkov mechanism of radiation is realized. Cherenkov instability in VFEL is described by the system of nonlinear equations of a special type. Let us consider the history of deriving this system. From two first Maxwell's equations in the approximation of slowly changing amplitudes in two-wave approximation we can derive the system of some equations having the form:

$$
\frac{\partial E}{\partial t}+A \frac{\partial E}{\partial z}+B \frac{\partial E}{\partial x}=F(j)
$$


where $E$ is the amplitude of electric field strength, $j$ is the beam current density.

These equations are connected by boundary conditions with respect to $z$. They are first-order PDEs too and can be obtained from the condition of continuity of tangential parts of electric and magnetic fields. In the case of two amplitudes $E_{1}$ and $E_{2}$ they have a form:

$$
A_{i}^{-} \frac{\partial E_{i}}{\partial t}+B_{i}^{-} \frac{\partial E_{i}}{\partial x}+C_{i}^{-} E_{i}+A_{k}^{+} \frac{\partial E_{k}}{\partial t}+B_{k}^{+} \frac{\partial E_{k}}{\partial x}+C_{k}^{+} E_{k}=f_{k}\left(x, t, E_{k}^{(0)}, j\right),
$$

where $i=1,2$ and $k=2,1$ for two boundaries with respect to $z . E_{k}^{(0)}$ is the amplitude of external incident to considered boundary wave.

Here we do not consider equations for distribution functions of electron beam and right-hand sides in (1.1) - (1.2). It is necessary to emphasize that the full system describing quasi-Cherenkov FEL is more complicated than (1.1) - (1.2). One can find more information about it in [4] and [7].

Equation (1.1) is the first-order partial differential equation with complex amplitude $E$ and real or complex coefficients before derivatives relative to $z$ and $x$. If $A$ and $B$ are real, we have pure hyperbolic equation. Such case was studied in [7], [8], [9]. If for example $A$ is complex, we deal with so called surface wave. This case was considered in [10], [11]. So, taking into account the structure of (2.4) it is the most correctly to call this equation with one complex coefficient as generalized transfer equation.

\section{PROBLEM FORMULATION}

We consider the following model problem:

$$
\begin{aligned}
& \frac{\partial u}{\partial t}+a \frac{\partial u}{\partial z}+b \frac{\partial u}{\partial x}=f, \\
& u(0, x, t)=u_{1}, \quad t>0, \\
& u(z, x, 0)=u_{0}, \quad 0 \leq z \leq L .
\end{aligned}
$$

The coefficient $a$ is complex-valued. Coefficient $b$ is a real number. Let us consider for the simplicity that $\operatorname{Re}(a)>0, \operatorname{Im}(a)>0, b>0$. We suppose the conditions of matching of functions $u_{0}, u_{1}$ and $f$ at $z=0$ and $t=0$ be fulfilled.

Considering the correctness of the problem (2.1), it is well-known [5] that the initial value problem for the Cauchy-Riemann system is ill-posed. So, in our case one should expect that the problem is ill-posed too. But we suppose the differential problem (2.1) has a unique bounded solution. And special conditions for $u_{0}, u_{1}$ and $f$ are fulfilled (e.g., $u_{0}(0, x)=u_{1}(x, 0)$, $f(z, x, 0)=0)$. In this case we can try to use numerical methods for our problem. 
Analysis of possible difference schemes for the test equation (2.1) with $b=0$ and $f=0$ was carried out in [10], [11]. It turned out that the good methods were the implicit scheme of the first-order approximation and weighted scheme. Stability for these schemes was investigated in these works. The validity of the condition for the implicit scheme was proved by numerical computations.

So, let us profit by these results for elliptic parts of our problem and previous results for hyperbolic problem. We propose difference schemes of the multicomponent modification of the alternating direction method (MMADM). This method was proposed in [1] and it is effective when operating with complex arithmetic. We applied MMADM for hyperbolic problems in [7], [8], [9]. Here for the simplicity we use notation from [6].

The scheme of MMADM for equation (2.1) can be written as

$$
\begin{aligned}
& y_{t}^{1}+a \hat{y}_{\bar{z}}^{1}+b y_{\bar{x}}^{2}=\hat{f}, \\
& y_{t}^{2}+a \hat{y}_{\bar{z}}^{1}+b \hat{y}_{\bar{x}}^{2}=\hat{f} .
\end{aligned}
$$

Here $y^{1}$ and $y^{2}$ are two components of approximate solution (2.1).

In this section, we discuss stability and convergence of numerical method $(2.2)-(2.3)$.

Let us introduce the following notation:

$$
y^{\prime}=\operatorname{Re}(y), \quad y^{\prime \prime}=\operatorname{Im}(y), \quad \bar{y}=y^{\prime}-i y^{\prime \prime} .
$$

Let define inner products:

$$
\begin{aligned}
& (y, v)_{\omega}=\sum_{i=1}^{N-1} h y_{i} v_{i}, \quad \omega=\left\{x_{i}=i h, i=0,1, \ldots, N, N h=L\right\} \\
& (y, v)_{G_{z x}}=(y, v)=\sum_{i=1}^{N_{1}-1} \sum_{j=1}^{N_{2}-1} h_{z} h_{x} y_{i j} v_{i j}, \quad G_{z x}=\omega_{z} \cup \omega_{x}
\end{aligned}
$$

and the norm:

$$
\|y\|=\sqrt{(y, y)}, \quad|y|^{2}=\left\|y^{\prime}\right\|^{2}+\left\|y^{\prime \prime}\right\|^{2} .
$$

Using the energy inequalities method we proved in [6], that the difference scheme (2.2)-(2.3) is stable relative to initial data and right-hand side. For its solution the following estimates hold:

$$
\left|\hat{y}^{i}\right|^{2} \leq M\left(\left|y^{i}(0)\right|^{2}+\left|a y^{1}(0)+b y^{2}(0)-f(0)\right|^{2}+\max _{t}\left(|f|^{2}+\left|f_{t}\right|^{2}\right)\right),
$$

where $M$ is a bounded positive constant independent of grid spacings, $i=1,2$. 
Such proof for hyperbolic equations was described in detail in [9] and especially in [12]. Let us repeat some computations. Multiplying (2.2) by $\tau \overline{a\left(y_{t}^{1}\right)}$, (2.3) by $\tau \overline{b\left(y_{t}^{2}\right)}$ and summing up, we obtain after some transformations:

$$
\begin{aligned}
\Phi(y) & +0.5\left\|a^{\prime}\left(\hat{y}_{\bar{z}}^{1}\right)^{\prime}-a^{\prime \prime}\left(\hat{y}_{\bar{z}}^{1}\right)^{\prime \prime}+b\left(\hat{y}_{\bar{x}}^{2}\right)^{\prime}-\hat{f}^{\prime}\right\|^{2} \\
& -0.5\left\|a^{\prime}\left(y_{\bar{z}}\right)^{\prime}-a^{\prime \prime}\left(y_{\bar{z}}\right)^{\prime \prime}+b\left(y_{\bar{x}}^{2}\right)^{\prime}-f^{\prime}\right\|^{2} \\
& +0.5\left\|a^{\prime \prime}\left(\hat{y}_{\bar{z}}\right)^{\prime}+a^{\prime}\left(\hat{y}_{\bar{z}}\right)^{\prime \prime}+b\left(\hat{y}_{\bar{x}}^{2}\right)^{\prime \prime}-\hat{f}^{\prime \prime}\right\|^{2} \\
& -\left\|a^{\prime \prime}\left(y_{\bar{z}}^{1}\right)^{\prime}+a^{\prime}\left(y_{\bar{z}}^{1}\right)^{\prime \prime}+b\left(y_{\bar{x}}^{2}\right)^{\prime \prime}-f^{\prime \prime}\right\|^{2} \\
& +0.5 \tau^{2}\left\|a^{\prime}\left(y_{\bar{z} t}^{1}\right)^{\prime}\right\|^{2}+0.5 \tau^{2}\left\|a^{\prime}\left(y_{\bar{z} t}^{1}\right)^{\prime \prime}\right\|^{2}+0.5 \tau^{2}\left\|a^{\prime \prime}\left(y_{\bar{z} t}^{1}\right)^{\prime}\right\|^{2} \\
& +0.5 \tau^{2}\left\|a^{\prime \prime}\left(y_{\bar{z} t}^{1}\right)^{\prime \prime}\right\|^{2}+0.5 \tau^{2}\left|b y_{\bar{x} t}^{2}\right|^{2} \\
& +\tau\left(\hat{f}^{\prime},\left(a^{\prime}\left(y \frac{1}{\bar{z}}\right)^{\prime}-a^{\prime \prime}\left(y_{\bar{z}}\right)^{\prime \prime}+b\left(y_{\bar{x}}^{2}\right)^{\prime}\right)_{t}\right) \\
& +\tau\left(\hat{f}^{\prime \prime},\left(a^{\prime}\left(y_{\bar{z}}\right)^{\prime \prime}-a^{\prime \prime}\left(y_{\bar{z}}\right)^{\prime}+b\left(y_{\bar{x}}^{2}\right)^{\prime \prime}\right)_{t}\right)=0,
\end{aligned}
$$

where

$$
\begin{aligned}
\Phi(y) & \left.\left.=\tau\left(y_{t}^{1}\right)^{\prime}, a^{\prime}\left(y_{\bar{z} t}^{1}\right)^{\prime}\right)+\tau\left(y_{t}^{1}\right)^{\prime \prime}, a^{\prime \prime}\left(y_{\bar{z} t}^{1}\right)^{\prime \prime}\right)+\tau\left(\left(y_{t}^{2}\right)^{\prime}, b\left(y_{\bar{x} t}^{2}\right)^{\prime}\right) \\
& \left.\left.+\tau\left(\left(y_{t}^{2}\right)^{\prime \prime}, b\left(y_{\bar{x} t}^{2}\right)^{\prime \prime}\right)-\tau\left(y_{t}^{1}\right)^{\prime}, a^{\prime \prime}\left(y_{\bar{z} t}^{1}\right)^{\prime \prime}\right)+\tau\left(y_{t}^{1}\right)^{\prime \prime}, a^{\prime \prime}\left(y_{\bar{z} t}^{1}\right)^{\prime}\right)
\end{aligned}
$$

Using Lemma 3.1 [12] it is easily to obtain that the first, second, third and fourth first components in (2.6) are greater than or equal to zero. For last two components taking into account boundary conditions, we can obtain

$\left.\left.\Psi(y)=\left(y_{t}^{1}\right)^{\prime}, a^{\prime \prime}\left(y_{\bar{z} t}^{1}\right)^{\prime \prime}\right)+\tau\left(y_{t}^{1}\right)^{\prime \prime}, a^{\prime \prime}\left(y_{\bar{z} t}^{1}\right)^{\prime}\right)=\frac{\tau a^{\prime \prime}}{h_{z}}\left(\left(y_{\left(N_{1}-1\right) t}^{1 \prime}\right)^{2}-\left(y_{\left(N_{1}-1\right) t}^{1 \prime}\right)^{2}\right)$.

In [11] we suggested the following condition of computing stability for the implicit scheme: $\tau|a|^{2} / h_{z} \geq 2 a^{\prime \prime}$. With its help one can show that

$$
\Psi(y)+0.5 \tau^{2}\left\|a^{\prime \prime}\left(y_{\bar{z} t}^{1}\right)^{\prime}\right\|^{2} \geq 0 .
$$

So, finally instead of $(2.5)$ we have:

$$
0.5\left|a \hat{y}_{\bar{z}}^{1}+b \hat{y}_{\bar{x}}^{2}-\hat{f}\right|^{2} \leq\left(1+C_{1} \tau\right)\left|a y \frac{1}{\bar{z}}+b y_{\bar{x}}^{2}-f\right|^{2}+C_{2}\left(|\hat{f}+f|^{2}+\tau\left|f_{t}\right|^{2}\right) .
$$

Then the proof of validity of the estimation (2.7) repeats the proof given in [9], [12]. The estimate (2.4) for $i=1$ is obtained in the same way as [9], [12].

We denote the discretization error as $z^{i}=y^{i}-u, i=1,2$, where $u$ is the exact solution of initial differential problem.

Let us suppose the differential problem (2.1) has a unique bounded solution. Then the solution of the difference problem (2.2)-(2.3) converges to the 
solution of initial differential problem as $\tau, h_{z}, h_{x} \rightarrow 0$. The discretization error may be written as

$$
\left|z^{i}\right| \leq O\left(\tau+h_{z}+h_{x}\right)
$$

Obtained theoretical results were used successfully in modelling of surface VFEL. We considered six equations of the form (1.1) with amplitudes $E_{i}, i=$ $1, \ldots, 6$, four boundary conditions of the form (1.2) and two simple boundary conditions. Boundary conditions are written on three boundaries at $z=0$, $z=L, z=-l$ ( $l$ is the thickness of relativistic electron beam). Making use of results of previous section, we have proposed difference schemes of type $(2.2)-(2.3)$ (see [4]).

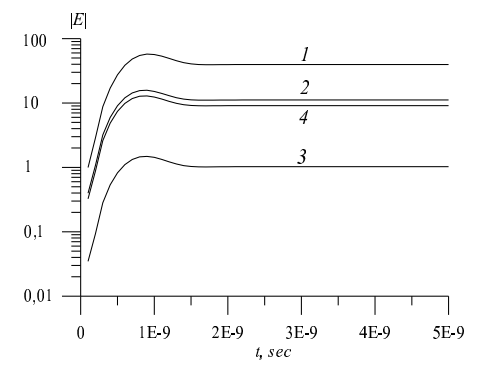

Figure 1. Amplification of electromagnetic fields as a function of time in visible surface quasiCherenkov FEL

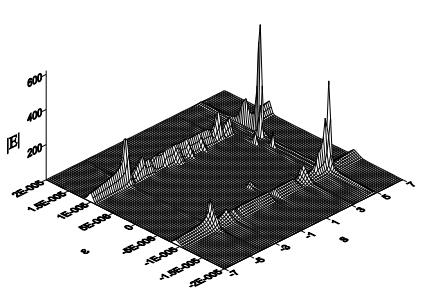

Figure 2. Attempt of optimization of the amplification process in visible surface quasi-Cherenkov FEL

\section{NUMERICAL EXPERIMENTS}

Now we discuss results of visible surface quasi-Cherenkov VFEL simulation. In Fig. 1 the amplification of electromagnetic fields as a function of time is represented. Lines 1 and 2 are related to the radiated wave amplitude on the grating (target) at $z=0$ and $z=L ; 3$ and 4 correspond to the diffracted wave at $z=L$ and $z=0$, respectively. From Fig.1 the achievement of saturation in radiation amplitude can be easily seen. The regime of saturation is very important in the nonlinear theory of VFEL. This figure shows that all solutions are bounded and stable.

Fig.2 demonstrates the attempt of optimization of the amplification process of the electromagnetic wave relative to the two parameters, the synchronism condition $\epsilon$ and the Bragg condition $s$ fulfillment. It is obvious that there is the optimal correlation between these two parameters where the amplification process is developed the most effective. Using this surface one can choose more working geometry for real physical experiment. All numerical results are in good agreement with analytical estimations form the physical point of view. 
In conclusion, difference scheme proposed in this article can be used for numerical solution of generalized transfer equation. It is stable and its solution converges to the solution of initial PDE. This difference scheme can be used in planning of real physical experiments on VFEL.

This work is in progress under State Program of fundamental investigation "Algorithm" and supported by INTAS (project INTAS-97 Ref. No:32041).

\section{REFERENCES}

[1] V. N. Abrashin. On a variant of alternating direction method for solving multidimensional problems of mathematical physics. I. Differential Equations, 26 1991, 316 - 323.

[2] V. G. Baryshevsky, K. G. Batrakov, I. Ya. Dubovskaya, S. N. Sytova. Visible surface quasi-Cherenkov FEL. Nucl. Instr. and Meth. in Phys. Res., A358 1995, $508-511$.

[3] V. G. Baryshevsky, K. G. Batrakov, I. Ya. Dubovskaya. Free Electron Lasers, 1996. Elsevier Science, 1997.

[4] I. Dubovskaya, V. Baryshevsky, K. Batrakov, S. Sytova. The nonliner analysis of visible quasi-Cherenkov FEL. In: 21th Intern. Free Electron Laser Conference (FEL99). Germany, http://www.desy.de/fel99/contributions/T05/ID_Mo-P-16.html, 1999.

[5] L. Hörmander. The analysis of linear partial differential operators I. , 1983.

[6] A. A. Samarskii. Theory of finite-difference schemes. M.: Nauka, 1989. (in Russian)

[7] S. Sytova. A numerical method for solving hyperbolic system with singularities. Differential Equations, 32 (7), 1996, 995 - 998.

[8] S. Sytova. Numerical solution of many-dimensional first-order hyperbolic system with specific boundary conditions. In: Intern. Conference PDE Prague'98, 1998, Book of Abstracts, 1998, 100.

[9] S. Sytova. A numerical method for solving one problem of nuclear physics. Vesti Nat. Acad. Sci. Belarus. Ser. Phys.-Math., 2 1993, $44-50$.

[10] S. Sytova. On Numerical Methods for Modelling of Terahertz Sources Based on Low Energy Relativistic Beams. In: Finite difference schemes:theory and applications, R. Ciegis, A. Samarskii and M. Sapagovas (Eds.), MII, Vilnius, 2000, 237-244.

[11] S. Sytova. Numerical methods in problems of modelling of volume free electron lasers. Differential Equations, 37 (7), 2001.

[12] S. Sytova. X-ray diffraction by time-dependent deformed crystals: theoretical model and numerical analysis. Electronic Journal Los Alamos (XXX.LANL.gov e-Print archive), (1999) .9901033

\section{Vieno mišraus tipo uždavinio skaitinis sprendimas}

\section{S. Sytova}

Straipsnyje tiriami mišraus tipo uždavinių sprendimo algoritmai. Nagrinëjama dvimatė pirmosios eilès diferencialinè lygtis, kurios vienas koeficiantas yra kompleksinè funkcija, o kitas - realaus tipo skaičius. Taigi uždavinys yra elipsinio tipo vieno kintamojo atžvilgiu ir hiperbolinio tipo kito kintamojo atžvilgiu. Ištirtas baigtinių skirtumų schemų stabilumas ir konvergavimas. Schemos realizavimui naudojamas dagiakomponentinis iteracinis metodas, ištirtas jo stabilumas. Pateikti matematinio modeliavimo rezultatai. 